\title{
Methods of validation of mirror system goniophotometers and its impact to the resulting LIDC regarding the energy performance of buildings
}

\begin{abstract}
L I D C$ is an important characteristic of luminaires used in the design of new lighting systems. Mirror system goniophotometers with are based on the principle of reflection of light emitted from luminaires on the mirrors. The accuracy of the LIDC measurement is influenced by many factors. This paper deals with measurement errors which occur with this type of goniophotometer, then methods of validation of goniophotometers using a mirror system is proposed. Based on these validation methods, accuracy of the LIDC measurement on goniophotometer with mirror system can be increased. This paper also deals with the impact of the choice of LIDC measured on goniophotometer with mirror system to the quality of interior lighting systems in the framework of the energy performance of buildings. The term energy performance of buildings means the amount of energy needed to meet all the energy needs associated with a standardized usage of the building.
\end{abstract}

Keywords: LIDC, goniophotometer, mirror system

\section{Introduction}

Every new lighting system is subject to verifications of photometric parameters, which is performed by measuring. These measurements are serving like a documents for Public health authority of the Slovak republic, whether a given lighting system is satisfactory for relevant regulations and whether is the area satisfying to the conditions of use. This check applies only to worskspaces. Before the implementation of lighting system in space is proposed project by light-technical calculation. In this time is design proposed by computer simulation software. Projectant needs to have relevant photometric data files for each used luminaires. He used this photometric data files for proposal of lighting system. This photometric data files must contain basic information about luminaire. This information are luminous flux, spatial characteristics of lighting source presented by LIDC and spectral composition of light emitted by the luminaire. These properties of luminaires have impact for resulting proposal and following realisation of lighting systems. LIDC is important parameter because is representing of spatial characteristic of lighting source or luminaire. By LIDC we can describe how is emitted light to the spatial. LIDC are measured by equipment with name goniophotometer and following are used to the lighttechnical calculation. Goniophotomers are used for measurement of spatial luminous intensity distribution of luminaires. I tis made one of the following principles:

- square law of distance (illuminance measurements at distances larger than the photometric distance)

- integration of luminance (measurement of local distribution of luminance on the surface of the luminaires at distances smaller than the photometric distance).

In practice it is used to the measure of LIDC more types of goniophotometers with different construction. Due to the fact is influenced accuracy of measurement of LIDC. Measured LIDC is in practice often "improved" and too wrong smoothed by software with mathematical methods. That is not always like reality. LIDC of luminaire is depending on construction of optical part of luminaire. This optical part directs the luminous flux from the light source into the space according to request of the lighting system. We can create desired LIDC with kind of optical components like a refractors or reflectors. There are no problems with using of traditional light sources. Problem is with using of LED light sources. In luminaires are formed local extremes in certain beam angles. That is main problem in some methods by measurement with goniophotometers. Measurements are sometimes oversimplified given to symmetry of the LIDC of luminaire according to some planes. This shortens the time of measurement. On the one side is economic effectivity growing up, but on the second side with wrong consideration of symmetry are provided inaccurate photometric files for light - technical calculation. On the accuracy of measurement have a impact of human factor. Can be for example inccorectly set luminaire before measurement, short distance from luminaire to sensor of luxmeter or wrong rotation of hand of goniophotometer. Is important to follow any principles for measurement of LIDC depending on the chosen methods and construction of goniophotometer. After that will be guaranteed correctly measurement. All of this have affects to the accuracy of photometric dates of luminaires.

\section{Light intensity distribution curve}

The task of reflector, refractor or diffuser is change of direction of beam in luminaire and lead the way of luminous flux to desired direction. In this way is changing original LIDC of light source to the LIDC of luminaire. By directing of light rays we can achieve practically any LIDC. We know a lot of types of LIDC. For example we can see four types in the pictures 1 and 2 :
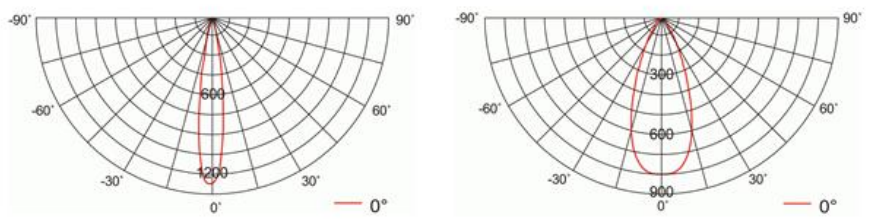

Fig. 1 Narrow and deep LIDC
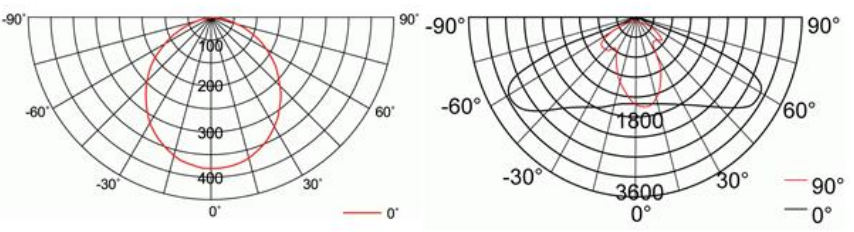

Fig. 2 Cosine and wide LIDC

Luminous intensity are emitted by light source to different directions and directed by optical system of luminaire are measured by goniophotometer and expressed for luminaire in unit of luminous intensity I [cd] and calculated for 1000 lumen light source [cd]. 
We have all of values of luminous intensity of luminaire. Now we apply this values spatially from the light middle of source like radiusvectors. We will be photometric luminous intensity are by merger all of these radiusvector. Thereby icurred lines (curves) of luminous intensity. Luminous intensity distribution curves are typically represented in polar plots because this format allows us to visualize both the orientation and the light distribution of the light fixture. The beginning of luminous intensity diagram is placed to the lighting center of source or luminaire. The basic direction of luminous intensity diagram, from which are angles measured, is placed in the direction of normal to main emission surface of light source or luminaire. LIDC are measured on the goniophotometer. Manufacturers of luminaires or light source given LIDC to the documentation.

\section{Symmetry of luminaires}

Horizontal axis is marked $\mathrm{C} 0-\mathrm{C} 180$ a vertical axis is marked $\mathrm{C} 90-\mathrm{C} 270$. In the picture 3 are planes graphically applied to the real luminaire.

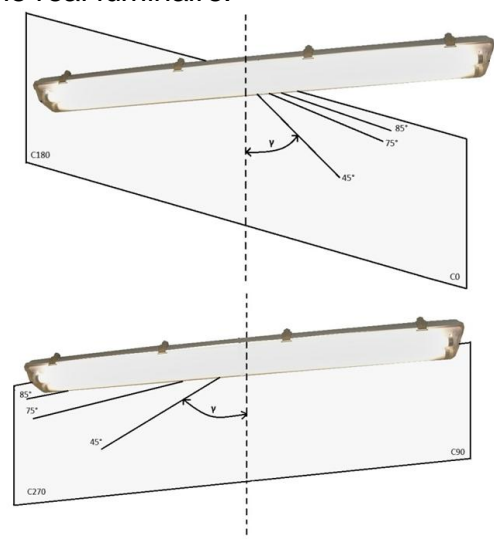

Fig. 3. Symmetry of LIDC

\section{Mirror system goniophotometer}

Principle of mirror system goniophotometer is in reflection of light beam emitted from luminaire by mirrors. We know more types of goniophotometrs. System can be formed with one or more mirrors. These goniophotometers have different construction. We know types with more construction. Which is type with moving sensor of luxmeter or is moving source of light. Which is type with static source of light or static sensor of luxmeter. Or a combination of moving and static components of goniophotometer. Mirrors of system can not confine the visibility from sensor of luxmeter to luminaire. They must be planar and have a constant spectral reflectance. Or their spectral reflectance must be taken into account in correcting $V(\lambda)$ of used photometric head.

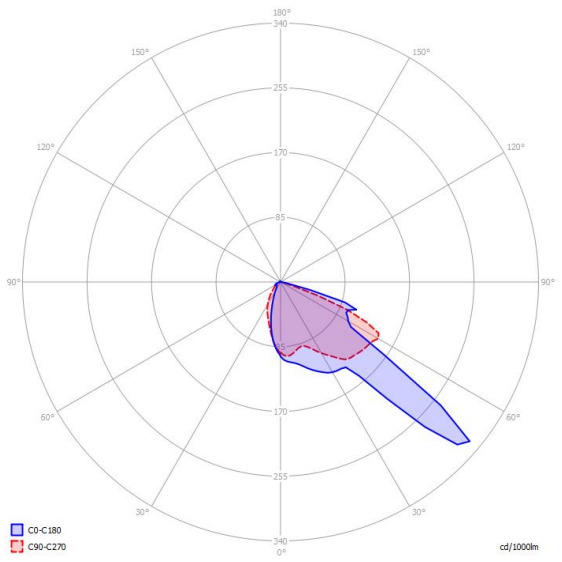

Fig. 4. LIDC measured with mirror system goniophotometer
Goniophotometer in our photometric laboratory have system of two mirrors rotating around horizontal axis. The light source is rotating around vertical axis. Sensor of luxmeter is fixed on photometric bench.

Care must be taken to polarization of emitted light. This emitted light is caused by the reflection from the mirror.

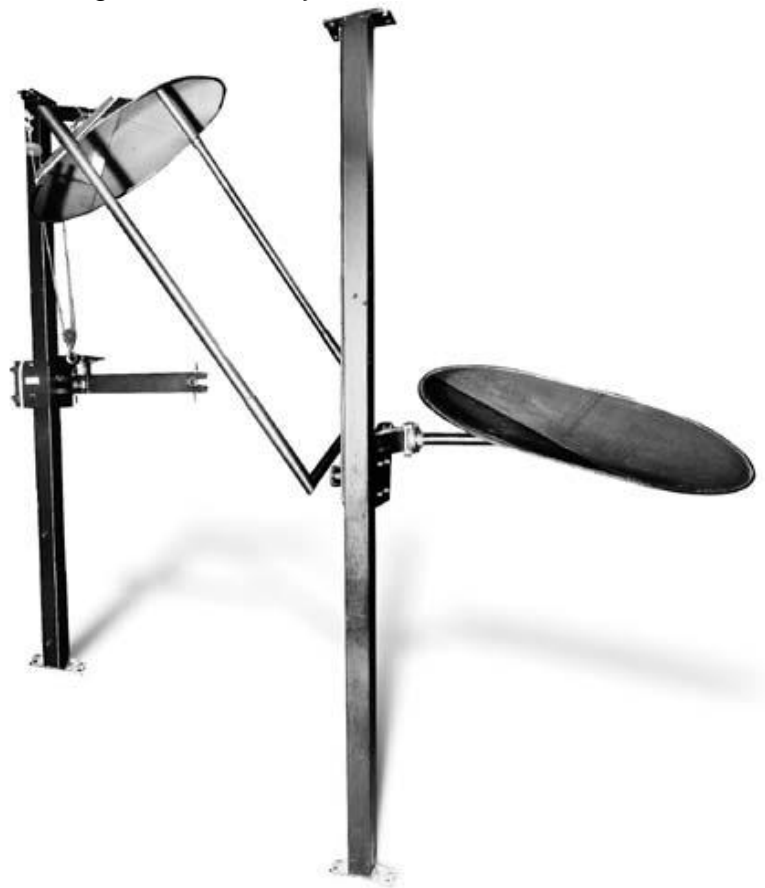

Fig. 5. Mirror system goniophotometer in photometric laboratory of FEI STU

\section{Measurement errors}

1. Incorrectly set of goniophotometer.

2. Wrong mounted light source or luminaire to the goniophotometer.

3. Wrong set of symmetry of light source of luminaire with sensor of luxmeter.

4. Short distance light source or luminaire from sensor of luxmeter.

5. Insufficient shading of undesired light and wrong preventing of reflections of emitted rays from light source or luminaire from surrounding materials.

6 . Incorrectly set of power supply voltage of light source or luminaire.

\section{Methods of validation of mirror system goniophotometers}

Firstly we must have clear mirrors. If we have clean mirrors we have better reflectivity. The correctly set of goniophotometer is when we have on the sensor of luxmeter the largest signal emitted from the light source or luminaire. This achieve by the correct inclination and rotate of mirrors from witch is the signal reflected. Our goniophotometer with mirror system is in combination with photometric bench with distance three meters. This photometric bench is symmetric with goniophotometer. Sensor of luxmeter is mounted on the photometric bench must be in symmetry with photometric middle of measured light source or luminaire. We can realized setting by laser. First we can set light source or luminaire on the goniophotometer. That means luminaire or light source must be set to the photometric middle in accordance with the goniophotometer. 


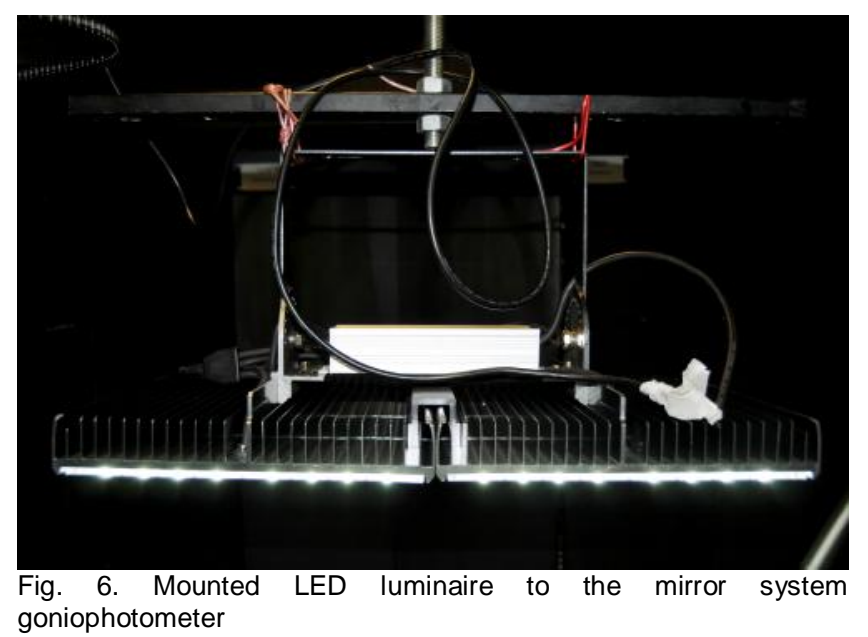

Then we put in the plane of laser beam reflected from the mirrors to the place of photometric middle of luminaire. Sensor of luxmeter must be in the place where passes through the laser beam. After correctly setting of sensor of luxmeter in symmetry with photometric middle of light source or luminaire, we neeed to ensure distance from sensor of luxmeter to luminaire. The smallest photometric working distance must be 5 times and more of the largest dimension of lighting parts of luminaire. When we measure LED light source photometric working distance must be 10 times and more of the largest dimension of lighting parts of luminaire. Finally we must shading reflecting rays emitted by the light source from surrounding materials. To the photometric bench we given baffles and we must set symmetry with sensor of luxmeter. The light source we connect to power supply voltage. We must wait for a stable electrical parameters. Now we can measure.

\section{Conclusion}

The resulting LIDC have large impact to the energy performance of buildings. If the designer has to disposition wrong photometric data files, illumination of the room will be incorrectly. That have impact to the energy performance of buildings. If the LIDC is measured wrongly, that means LIDC have different shape like original, designer proposed room with more luminaires and then will be increased electrical consumption. Another negative reason may be by incorrect measurement of LIDC. For example wrong light output ratio of luminaire and then wrong proposal for illuminated room.

This paper is supported by the agency VEGA MŠVVaŠ SR under Grant No. VEGA 1/0988/12 „Energy efficiency of lighting systems in buildings“"

\section{REFERENCES}

[1] STN EN 12464 - 1: 2004 Svetlo a osvetlenie. Osvetlenie pracovných miest. Čast' 1: Vnútorné pracovné miesta.

[2] HORÑÁK P.: Svetelná technika; Alfa, Bratislava, 1989

[3] KRASŃAN, F.: Measurements of luminous parameters of luminaires in authorized testing laboratory using a computer-driven goniophotometer; In Proceedings: Svetlo - Light, Jasná, 2009, pp. 406-414, ISBN 978-80-969403-7-0

[4] International Vocabulary of Metrology, JCGM 200:2012, BIPM

[5] BERGEN, T.: Measurement and use of luminous intensity distributions; In: Razsvetljava 2013: Dvaindvajseto mednarodno posvetovanje. Bled Slovenia 2013, pp. 51-58, ISBN 978-961-248400

[6] KROPÁČ, M. - VESELOVSKÝ, J.: Analýza reflektorových svietidiel; In: Svetlo - Light, Brno, 2004, s. 150-154, ISBN 80-2388928-1

\section{Authors:}

Ing. Lukáš Grinaj, Slovak university of technology, Faculty of electrical engineering and information technology, Ilkovičova 3, 812 19 Bratislava, Slovak republic, e-mail: lukas.grinaj@stuba.sk

Mgr. Roman Dubnička, Slovak university of technology, Faculty of electrical engineering and information technology, Ilkovičova 3, 812 19 Bratislava, Slovak republic, e-mail: roman.dubnicka@stuba.sk

Prof. Ing. Alfonz Smola, PhD, Slovak university of technology, Faculty of electrical engineering and information technology, Ilkovičova 3, 81219 Bratislava, Slovak republic,

e-mail: alfonz.smola@stuba.sk 